\title{
Considering wind speed variability in real-time voltage stability assessment using
} Thévenin equivalent methods

Perez, Angel; Karatas, Bahtiyar Can; Jóhannsson, Hjörtur; Østergaard, Jacob

Published in:

Proceedings of 2017 IEEE Manchester PowerTech

Link to article, DOI:

10.1109/PTC.2017.7980951

Publication date:

2017

Document Version

Peer reviewed version

Link back to DTU Orbit

Citation (APA):

Perez, A., Karatas, B. C., Jóhannsson, H., \& Østergaard, J. (2017). Considering wind speed variability in realtime voltage stability assessment using Thévenin equivalent methods. In Proceedings of 2017 IEEE Manchester PowerTech IEEE. https://doi.org/10.1109/PTC.2017.7980951

\section{General rights}

Copyright and moral rights for the publications made accessible in the public portal are retained by the authors and/or other copyright owners and it is a condition of accessing publications that users recognise and abide by the legal requirements associated with these rights.

- Users may download and print one copy of any publication from the public portal for the purpose of private study or research.

- You may not further distribute the material or use it for any profit-making activity or commercial gain

- You may freely distribute the URL identifying the publication in the public portal 


\title{
Considering wind speed variability in real-time voltage stability assessment using Thévenin equivalent methods
}

\author{
Angel Perez, Bahtiyar Can Karatas, Hjörtur Jóhannsson and Jacob Østergaard
}

\begin{abstract}
In this paper, wind speed models are used to consider its variability in real-time voltage stability assessment using Thévenin equivalent methods. A stochastic differential equation was used to produce a set of wind speeds required for the simulation scenarios together with a very short-term forecast based on a probabilistic method, which provides the means for including anticipation in the stability assessment. This is achieved by representing the variation in the wind as an uncertainty in the Thévenin equivalent parameters, which are used for wide-area assessment, and studying corresponding changes in the stability boundary for a specific time horizon. The methodology was tested with time domain simulation a cigré benchmark system for network integrations of renewables, where the approach successfully represented the final Thévenin Equivalent parameters with a maximum error of $2.5 \%$ of the estimated variables, for a time horizon of 1 minute in the used forecast.
\end{abstract}

Index Terms-Voltage stability, Real-time, uncertainty, Stability limit, Wind speed, Wide-Area

\section{INTRODUCTION}

It is expected that a higher percentage of power generation will come from wind energy in Denmark [1] and its variability will impose challenges in the power system control and stability, where some of those concerns are aimed to be addressed by the SOSPO project ${ }^{1}$. For this purpose, a set of algorithms have been developed to produce a fast stability assessment, in real-time, by using PMU (Phasor Measurement Units) and wide-are information [2-10].

In the specific case of voltage stability, two methods were identified as suitable for real-time assessment [5]: sensitivities and Thévenin Equivalent methods, and a review of existent approaches can be found in [11]. The real-time voltage stability assessment in this paper is based on Thévenin equivalent method $[2,5,11]$, which offers advantages in its computational complexity [5] and its element-wise nature is used to consider the limits in the generators as described in [6]; the improvements described in [9] make it suitable for considering wind farms limits.

To take into account the generation variability due to the wind speeds, the stochastic differential equation models

This work has received funding from the Danish Council for Strategic Research as a part of the project Secure Operation of Sustainable Power Systems (SOSPO)

${ }^{1} \mathrm{http} / / /$ sospo.dk/

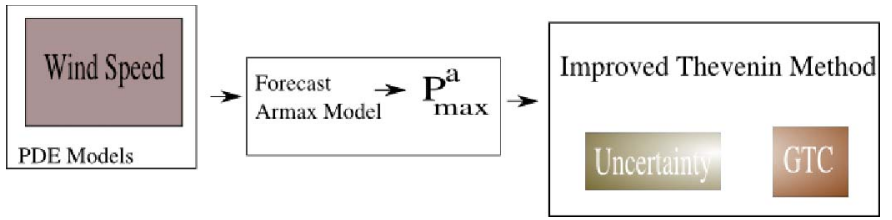

Figure 1. Process for the simulation of wind

presented in [12] allowed to produce a set of wind-speed time series, in the desired time-frame for the simulations. In the very-short term time frame for the wind, a probabilistic method for wind power forecast $[13,14]$ is suitable and was used to determine the future value of the wind generation. The forecast and the associated uncertainty allows to compute the Thévenin equivalent parameters and its uncertainty. This is achieved by using the work developed, which considers the PMU accuracy in real-time stability assessment [6] as a framework to study the variability of the voltage stability index.

The main objective was to show the possibility of considering the variability of the wind as an uncertainty of the estimated Thévenin Equivalent, and the associated implications it has on the index. This method is tested based on time domain simulations and synthesized PMU measurements and it shows how the uncertainty plays a crucial role in the validity and interpretation of the estimated stability indexes.

\section{Methodology}

\section{A. Proposed method overview and contribution}

This paper is an extension of the methods developed in [5-9], Fig. 1 offers an overview of the adaptations that are suggested in this work, in order to take into account the variability of the wind in the real-time stability assessment.The proposed algorithms is the following:

- Use the available wind speed or available maximum power to forecast the maximum available power for the studied time horizon. In this paper, the used wind speeds are produced from a simulation described in section III-A.

- Use the forecasted value to estimate the maximum power available in the selected time horizon, in order to estimate the new Thévenin equivalent considering the generators limits by using the methods described in [7, 9].

- Use the uncertainty of the produced forecast to evaluate the impact of the variability of the wind speed on the volt- 


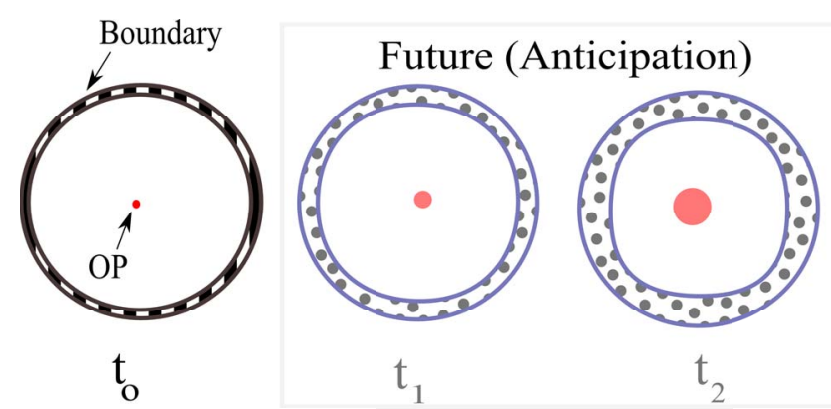

Figure 2. Variations of the stability boundary as a function of time horizon, where OP is the current $\left(t_{0}\right)$ operation point and the diagrams show the increase in uncertainty on the boundary due the forecast for future times $t_{1}$ and $t_{2}$

age stability index by using the methodology developed in [6].

The proposed modifications are related to the limitations of the work developed in [9], namely: the maximum power that can be injected was computed based on the current measurement and the maximum current of the converter ${ }^{2}$. This work is intended to provide some anticipation capabilities by including the forecast, with different time horizons. The expected output is depicted in Fig.2, where an abstraction of the boundary and the operation point serves to explain the effect of uncertainty in the forecast, and on the anticipations features added to the method.

\section{B. Premises}

Since the objective is to explore the possibilities that are given by the use of PMU measurements in the future system, the premises are expressed explicitly and marks the scope of the work:

- Full observability of the system, provided by PMU measurements. It is envisioned that PMUs will increase its number of installed units and the system will be observable, having a snapshot of the system between the cycle time-frame (20ms for $50 \mathrm{~Hz}$ system).

- Increased penetration of wind generation that is complying with the actual connections requirements regarding voltage control in Denmark, in specific [16].

\section{Algorithm testing methodology}

In order to test the proposed method and assess the impact of wind speed variability on real-time stability assessment, the following methodology was used:

- The continuous model developed in [12] is used to generate the wind speed scenarios that will be used to evaluate the methodology.

- The wind speeds are transformed into maximum power available from wind, using the wind turbine characteristics

- A statistical forecast for very short-term application is used to predict the future values of Pmax based on an

\footnotetext{
${ }^{2}$ In this work Type 4 wind generator are consider, therefore only the maximum current that can be injected was used in the modeling $[9,15]$
}

Table I. PARAMETERS USED IN THE SIMULATION OF THE WINDSPEEDS,

TAKEN FROM [20] FOR THE DESIRED TIME FRAME

\begin{tabular}{l|c|c|c} 
Parameters & $\alpha$ & $\lambda$ & $k$ \\
\hline \hline Values & $2.65 \mathrm{e}-5$ & 10.67 & 1.77 \\
\hline
\end{tabular}

ARMAX model that is computed from previous observations. The uncertainty of the estimated Pmax is obtained.

- The expected uncertainty in the wind power and the effect of generator limits are considered by using and combining the methodologies described [5-10]

- The separate elements of the methodology are tested and evaluated

- The overall methods and its effects on voltage stability assessment are studied on the Cigre benchmark model[17].

The details of the used algorithms and modeling for the simulations are included in section III.

\section{MODELING AND ALGORITHMS}

\section{A. Wind profile simulation and forecast}

For power system security assessment application the time span of minutes is of interest [18], which is clasified as very-short term prediction horizon for the forecast. In order to perform meaningful simulation, the stochastic differential equation and the model presented in [12] were used to produce a set of Wind speed series in the desired time frame. The maximum power that can be provided by this wind-farm will have the distribution given by the windspeed in Fig. 4 and It is expected that the maximum power will be affected by this variability for high penetration of wind power.

To obtain the set wind profiles, the stochastic differential equations (SDE) that describe the wind-speed is given by [12]:

$$
d y(t)=-\alpha y(t) d t+b d W(t), \forall t \in[0, T]
$$

where, $\mathrm{y}(\mathrm{t})$ is an autocorrelated Gaussian diffusion process and will be distributed as $N\left(0, \frac{b}{2 \alpha}\right)$. This SDE is solved by using Euler-murayama method [19]. Finally, to obtain the wind speed the process has to be transformed to a Weibull autocorrelated process and therefore the following memoryless transformation needs to be used [12]:

$$
x(t)=F^{-1}\left(\Phi\left(\frac{y(t)}{b \sqrt{2 \alpha}}\right)\right), \forall t \in[0, T]
$$

where $F^{-1}$ is the weibull cumulative distribution function and $\Phi$ is the Gaussian cumulative distribution function.

In order to obtain valid wind speed characteristics, the parameters of (2) has to be selected, and the used parameters are shown in Table III-A.

One solution of (1) and successive use of (2), can give a single synthetic wind speed time series as the one shown in Fig. 3. If multiple solutions are computed, a set of wind speeds paths are produced ${ }^{3}$, the result of such set is shown in Fig. 4

\footnotetext{
${ }^{3}$ A single solution of a SDE is called path in [19], and the author keep that convention
} 
for the wind as an histogram, with characteristic described in Table III-A.

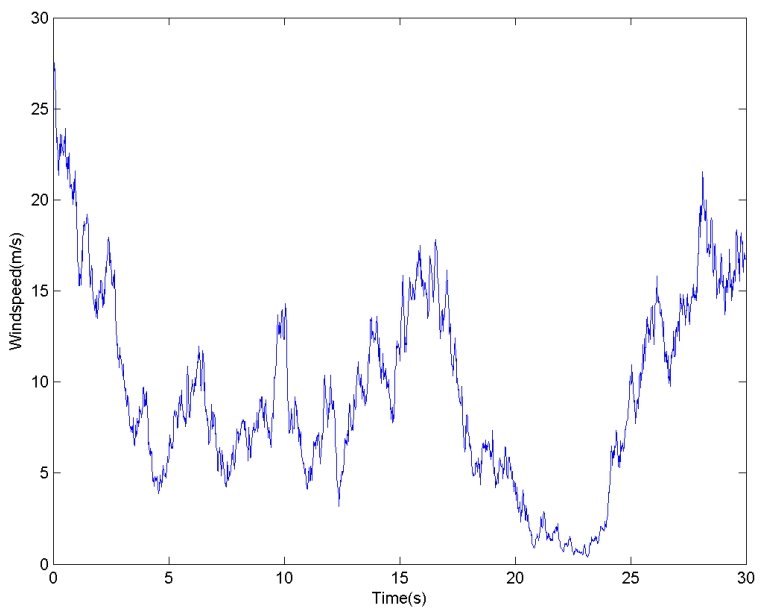

Figure 3. Single wind speed time series obtained by solving 1

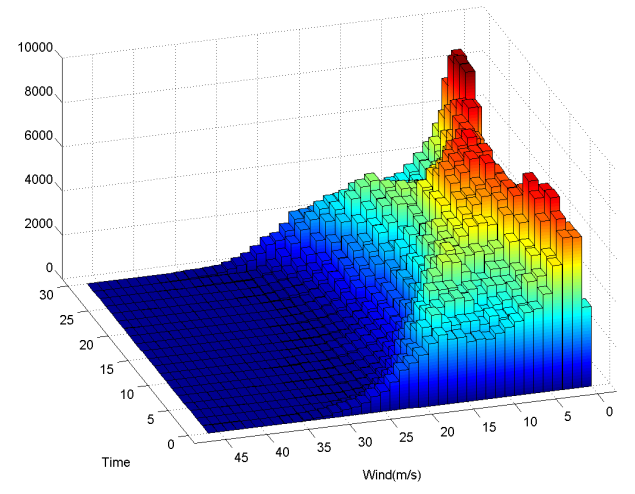

Figure 4. Wind speed histogram (Speed vs Time vs $\mathrm{N}$ occurrences) in a set of paths

The final goal is to use the set of winds speeds to assess the performance of the algorithms, this will be achieved by using a Monte Carlo approach (many path study), in which each wind-speed will be regarded as a sample for which the voltage stability index will be studied. To be used in simulations, the wind speeds are converted to maximum power that can be delivered by using the characteristic of the wind turbine in [21].

The simplified characteristic that is shown in Fig. 5, implies that for windspeeds $v_{i n}<v<v_{n}$, the output power will be computed with the models described in [21], using the average wind speed as an input.

\section{B. Very short-term wind forecast and uncertainty}

The other application of the synthesized wind speeds, is that it allows testing of the forecast methods and additionally evaluate the produced uncertainty. The selected method was a statistical method, since it is well suited for very-short term

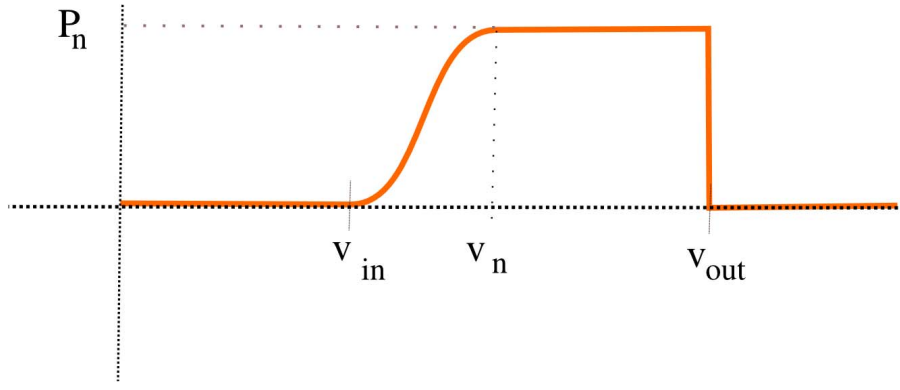

Figure 5. Wind speed vs Power output characteristic

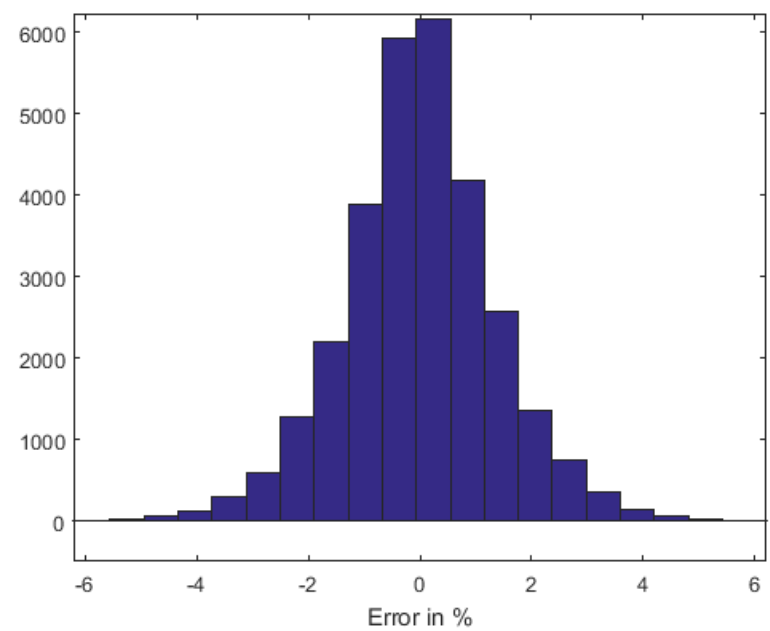

Figure 6. Error distribution for the forecasted values for 1s time horizon, Error $=\frac{y_{f}-y_{r}}{\overline{y_{r}}}$. where $r$ denotes reference values and $f$ denotes forecasted values

forecasts $[13,18]$, in particular an ARMAX model was used and the uncertainty for different prediction horizons are shown in Table. III-B, with the corresponding NRMSE (Normalized root mean squared error). The distribution of the error can be appreciated in Fig. 6 and corresponds to the distributions that were studied for the uncertainty in PMU measurements in [6]. For that reason, the methods proposed in [6] are used.

Table II. EVAluation OF THE UnCERTAinty AND THE QUALity OF THE FIT USING THE ARMAX MODELS FOR DIFFERENT TIME HORIZONS, THE USED WINDOWS ARE THE SAME SIZE OF THE FORECASTED TIME HORIZON

\begin{tabular}{l|c} 
Time Horizon (s) & $N R M S E(\%)$ \\
\hline \hline $1 \mathrm{~s}$ & 97.64 \\
$30 \mathrm{~s}$ & 87.78 \\
$60 \mathrm{~s}$ & 83.45 \\
$300 \mathrm{~s}$ & 62.65 \\
\hline
\end{tabular}

\section{Modeling for TEM methods Wind generator voltage control}

In this section, the modeling of the wind generator limits used for real-time voltage stability assessment is presented. As identified in $[5,7,9]$, the critical conditions regarding long-term voltage stability assessment is the activation of generator limits and (e.g. OEL in synchronous generators, 
Imax for inverter based converters) and the corresponding reduction of the maximum power that can be delivered to the buses. Therefore, the voltage control scheme and the requirement for wind farms are of interest for this work. The used specifications ${ }^{4}$ are in [16] and it suggest a droop characteristic as the one is shown in Fig. 7.

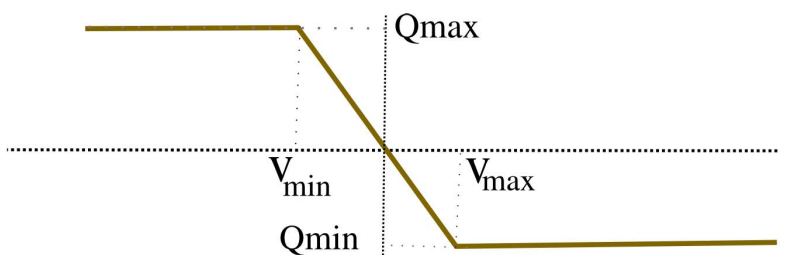

Figure 7. Droop characteristic for the voltage control of the wind generators, where the values used where $V_{\max }=1.1, V_{\min }=0.9$ and $Q_{\max }=$ $\sqrt{\left(V I_{\max }\right)^{2}-P^{2}}$

Regarding the modeling of the wind generation, in $[9,10$, 15] it was shown that type 4 wind turbines and HVDC links (VSC based) can be represented for the real-time long voltage stability assessment by a current source. This current source in conjunction with the generator transformation coefficients and wide-are information from PMU measurements, allows to estimate the equivalent at a given bus following the procedures in $[6,7,9]$, which is ready to include the uncertainty and produce a voltage stability limit.

\section{Study CASES AND RESUlts}

The benchmark networks presented in [17], the european distribution network was selected to test the algorithm and its modified version used in this paper, including Distributed generation (DG), is shown in Fig. 8. Using the network presented in Fig. 8, the objectives of the study case are two fold:

- Use a representative set of wind speeds to represent the variability of wind generation.

- Simulate an event that will triggers the limit activation in the studied generator and thus serve as a test condition and system.

To obtain the required response, the MV sub-transmission grid was substituted by the equivalent network (Thévenin Equivalent) of the nordic system [22], including the Thévenin Impedance for bus 1041 (Critical Bus) and the voltage time series for the following contingency: three phase fault in the line from 4032-4044 at $\mathrm{t}=1 \mathrm{~s}$, near bus 4044 and cleared at $\mathrm{t}=1.1 \mathrm{~s}$ by opening line $4032-4044$. The voltages appearing in the distribution network in Fig. 8 when no DG's are connected is shown in Fig. 9.

In the case that the DG's are included, the voltage is dropping and according to the droop characteristic in Fig. 7 the DG's should find their maximum of current and their $Q_{\max }$ respectively. For a single set of wind speeds and DG's of Pmax $=250 \mathrm{~kW}$ per phase connected to each bus, the behavior

\footnotetext{
${ }^{4}$ Part of the premises includes the increase of wind generation, which hast to comply with existing connections requirements
}

HV-MV moberenemisoslon network $110 \mathrm{kV}$

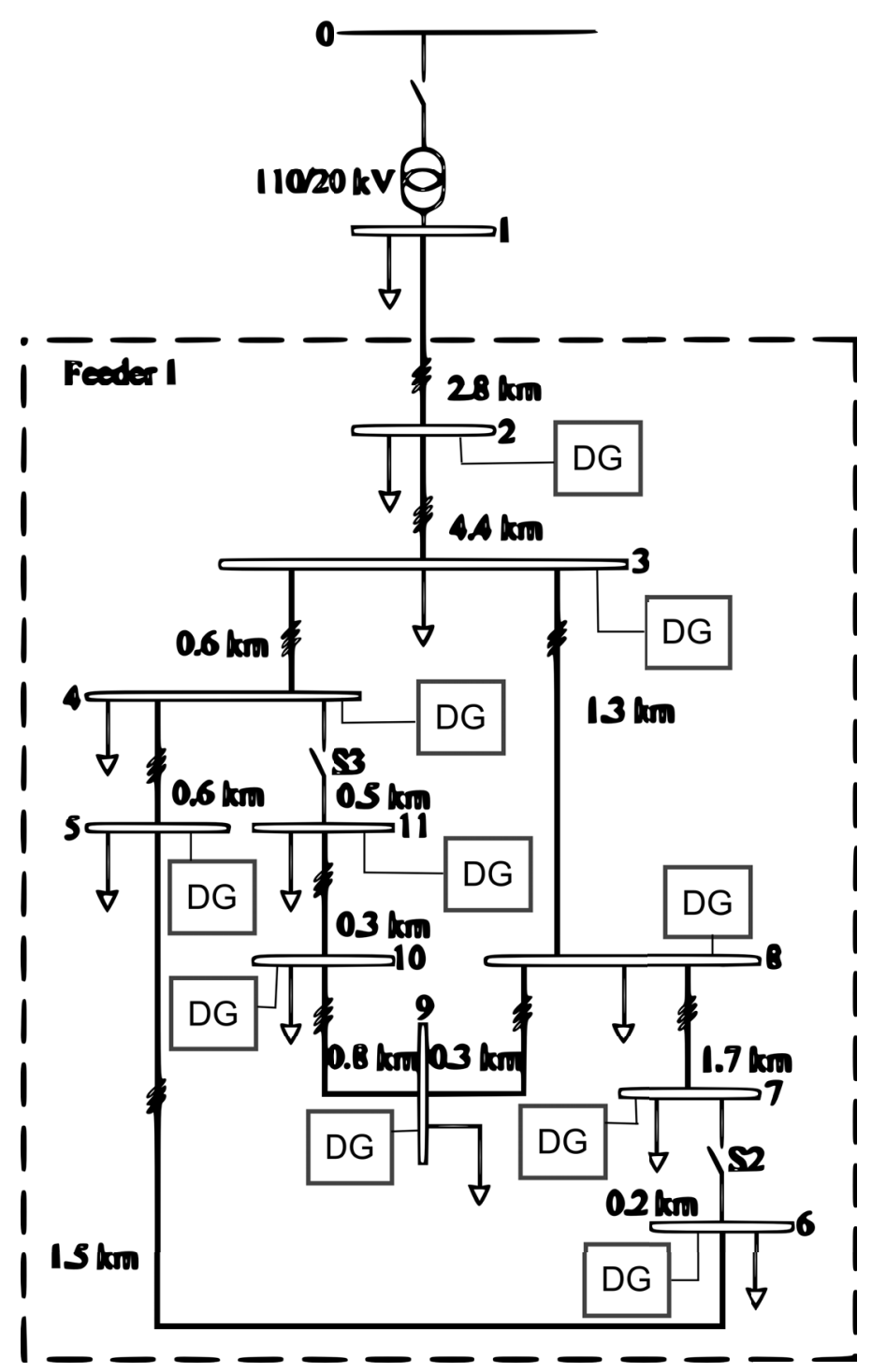

Figure 8. The benchmark networks presented in [17]

of the voltage control loop can be considered as the injected Q of each generator as shown in Fig. 10. This scenario, has the desired characteristic and will serve to benchmark the method characteristics.

From the set of wind speeds, a group of 100 simulations were performed. All the simulation were carried out in Matlab Simulink, where the system model was developed and tested. These simulations will help to estimate statistically the performance of the estimated Thévenin equivalent as described in this paper. The results of the simulations are the error between the forecasted Injected current angle and the actual Injected current angle ${ }^{5}$, the computed value is the maximum error over all simulations and the distribution for $T_{\text {horizon }}=1 \mathrm{~s}$ is shown in Fig. 11. The results for all time horizons are summarized

\footnotetext{
${ }^{5}$ The magnitude at the moment of the activation of the limit will be $I_{\max }$
} 


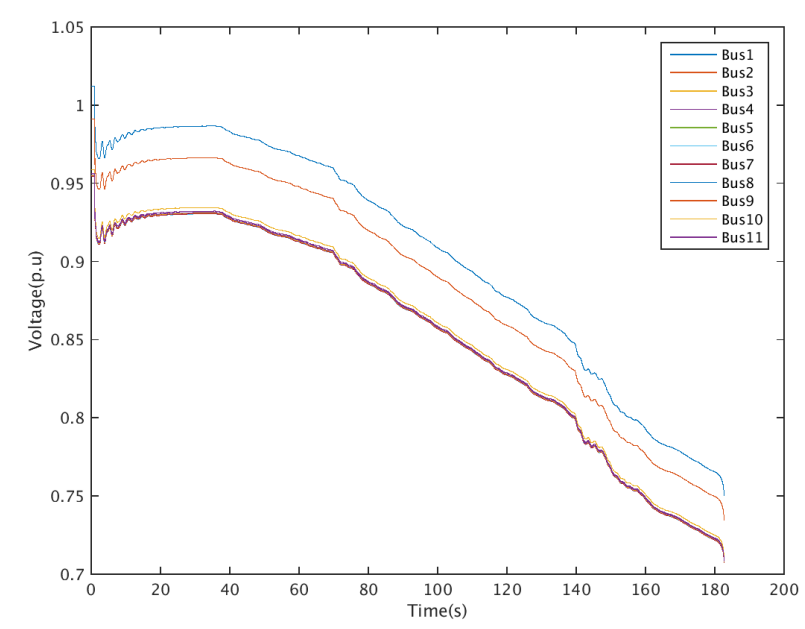

Figure 9. Voltage in per unit for the base case, no distributed generation active

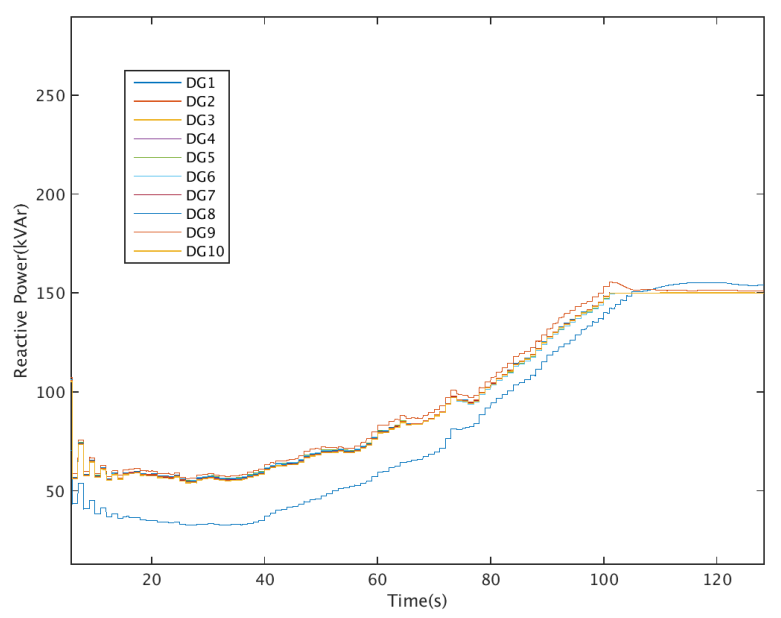

Figure 10. Reactive Power injected by the DG's, when the Pmax $=250 \mathrm{~kW}$ per phase $(\operatorname{Imax}=21.65 \mathrm{~A})$

in Table IV and corresponds to the distributions used in [6] to characterize the uncertainty of the Thévenin equivalent.

Table III. MAXIMUM ERROR MEAN AND STANDARD DEVIATION USED FOR THE UNCERTAINTY MODELING SUGGESTED IN [6]

\begin{tabular}{l|c|c} 
Time Horizon (s) & average & Standard Deviation \\
\hline \hline $1 \mathrm{~s}$ & 2.15 & 0.48 \\
$30 \mathrm{~s}$ & 2.26 & 0.52 \\
$60 \mathrm{~s}$ & 2.46 & 0.60 \\
\hline
\end{tabular}

\section{CONCLUSIONS}

The results show that it is possible to use a statistical forecast (i.e ARMAX model) to estimate the future angle of the injected current (used in the improved Thévenin Equivalent methods described $[6,7])$ and in that way obtain an anticipated value of the maximum current that will be injected when

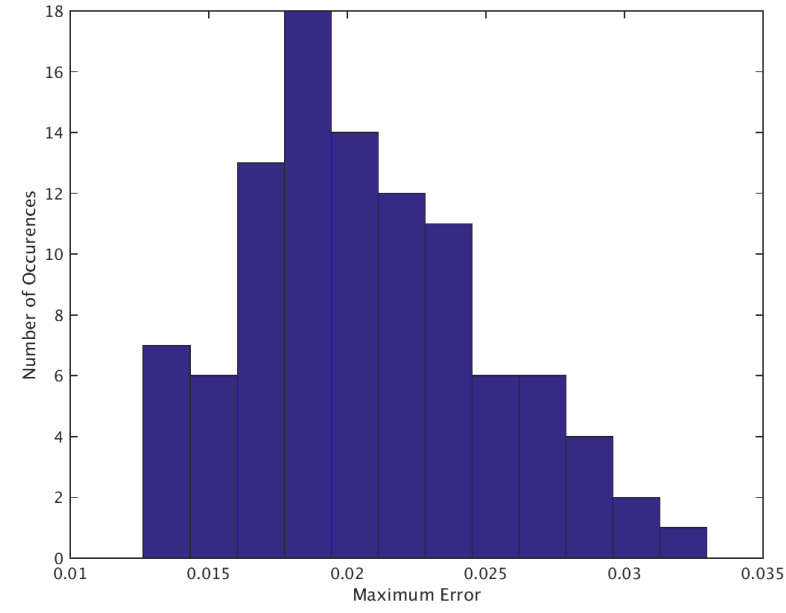

Figure 11. Distribution of the Maximum error over all simulations for $T_{\text {horizon }}=1 \mathrm{~s}$

the generator reaches its limit. The incurred uncertainty was computed and described in terms of the methodology found in [6], with values that are less than 3\% with the used forecast.

\section{LIMITATIONS AND FUTURE WORK}

When this work was finished, a set of questions and improvements were formulated, based on the work limitations:

- The forecast used is a simple model, more sophisticated approaches are available in the literature [14], which will prove worth it for longer time horizons.

- The range of seconds were of interest in the generator limit studies carried out in [7]; However, when the operation of the transformers tap changers and the load characteristics (e.g. load recovery) are included, the minute range also has to be considered for the forecast and wind generation impact.

- The simple scheme to compute the contribution of the wind generator when its limit is activated, depends on the locality and simplicity of the assumed controller (only dependent on local voltage and a simple droop characteristic). On the presence of a centralized control, this scheme will need modification to estimate when the generator will be limited.

These limitations are planned to be addressed in future work, and additional modifications to the proposed methods are envisioned.

\section{ACKNOWLEDGMENTS}

The authors will like to thank Thierry Van Cutsem and Mevludin Glavic for their collaboration in supplying the required information regarding the Nordic System.

\section{REFERENCES}

[1] M. Trong, K. Nørregaard, J. Østergaard, P. Bach, M. Lind, P. Sørensen, B. Tennbakk, M. Togeby, and T. Ackermann, "Ecogrid.dk phase i summary report: 
Steps towards a danish power system with $50 \%$ wind energy," in Energinet.dk, Tech Report, October 2009.

[2] S. Sommer and H. Johannsson, "Real-time thevenin impedance computation," 2013 IEEE PES Innovative Smart Grid Technologies Conference (ISGT), pp. 1-6, Feb. 2013.

[3] E. Dmitrova, M. Wittrock, H. Johannsson, and A. Nielsen, "Early prevention method for power system instability," Power Systems, IEEE Transactions on, vol. 30, no. 4, pp. 1784-1792, July 2015.

[4] T. Weckesser, H. Johannsson, and J. Ostergaard, "Realtime remedial action against aperiodic small signal rotor angle instability," Power Systems, IEEE Transactions on, vol. PP, no. 99, pp. 1-10, 2015.

[5] A. Perez, H. Jóhannsson, P. Vancraeyveld, and J. Østergaard, "Suitability of voltage stability study methods for real-time assessment," in Innovative Smart Grid Technologies Europe (ISGT EUROPE), 2013 4th IEEE/PES, Oct 2013, pp. 1-5.

[6] A. Perez, J. Møller, H. Jóhannsson, and J. Østergaard, "Uncertainty in real-time voltage stability assessment methods based on Thévenin equivalent due to PMU's accuracy," in Innovative Smart Grid Technologies Conference Europe (ISGT-Europe), 2014 IEEE PES, Oct 2014, pp. 1-6.

[7] A. Perez, H. Jóhannsson, and J. Østergaard, "Evaluation of enhancements to Thévenin equivalent based methods for real-time voltage stability assessment," in Innovative Smart Grid Technologies Conference Europe (ISGTEurope), 2014 IEEE PES, Oct 2014, pp. 1-5.

[8] A. Perez, H. Jóhannsson, K. Martin, and J. Østergaard, "Improved method for considering PMU's uncertainty and its effect on real-time stability assessment methods based on Thévenin equivalent," in PowerTech, 2015 IEEE Eindhoven, June 2015, pp. 1-5.

[9] A. Perez, H. Jóhannsson, and J. Østergaard, "Wind farms generation limits and its impact in real-time voltage stability assessment," in PowerTech, 2015 IEEE Eindhoven, June 2015, pp. 1-5.

[10] — - "Evaluation of HVDC interconnection models for considering its impact in real-time voltage stability assessment," in IEEE MEPS 2015, Wroclaw, 2015, pp. 15.

[11] M. Glavic and T. V. Cutsem, "A short survey of methods for voltage instability detection," Power and Energy Society General Meeting, pp. 1-8, 2011.

[12] R. Zárate-Miñano, M. Anghel, and F. Milano, "Continuous wind speed models based on stochastic differential equations," Applied Energy, vol. 104, pp. 42-49, Apr. 2013.

[13] G. Giebel, "The state-of-the-art in short-term prediction of wind power," in ANEMOS project WP-1, November 2003.

[14] J. Tastu, H. Madsen, and P. Pinson, "Short-term wind power forecasting: probabilistic and space-time aspects," Ph.D. dissertation, 2013.
[15] L. Zeni and H. Jóhannsson, "Influence of current limitation on voltage stability with voltage sourced converter HVDC," IEEE PES ISGT Europe 2013, pp. 1-5, 2013.

[16] Energinet.dk, "Technical regulation 3.2.5 for wind power plants with a power output above $11 \mathrm{kw}$," in Regulation for grid connection, June 2015.

[17] Benchmark systems for network integration of renewable and distributed energy resources. Paris (21 rue d'Artois, 75008): CIGRE, 2014.

[18] S. Rebennack, Handbook of power systems. Berlin Heidelberg: Springer, 2010.

[19] D. J. Higham., "An algorithmic introduction to numerical simulation of stochastic differential equations," SIAM Review, vol. 43, no. 3, pp. 525-546, 2001. [Online]. Available: http://dx.doi.org/10.1137/ S0036144500378302

[20] R. Zárate-Miñano, M. Anghel, and F. Milano, “Continuous wind speed models based on stochastic differential equations," Applied Energy, vol. 104, pp. 42-49, Apr. 2013.

[21] M. Singh and S. Santoso, Dynamic Models for Wind Turbines and Wind Power Plants. 1617 Cole Boulevard Golden, Colorado 80401: NREL, National Renewable Energy Laboratory, 2011.

[22] M. Glavic and T. Van Cutsem, "Wide-Area Detection of Voltage Instability From Synchronized Phasor Measurements. Part II: Simulation Results," IEEE Transactions on Power Systems, vol. 24, no. 3, pp. 1417-1425, Aug. 2009. 